\title{
Characterization of fracture patterns and hygric properties for moisture flow modelling in cracked concrete
}

Rouchier, Simon; Janssen, Hans; Rode, Carsten; Woloszyn, Monika; Foray, Geneviève; Roux, JeanJacques

\section{Published in:}

Construction and Building Materials

Link to article, DOI:

10.1016/j.conbuildmat.2012.02.047

Publication date:

2012

Document Version

Publisher's PDF, also known as Version of record

Link back to DTU Orbit

Citation (APA):

Rouchier, S., Janssen, H., Rode, C., Woloszyn, M., Foray, G., \& Roux, J-J. (2012). Characterization of fracture patterns and hygric properties for moisture flow modelling in cracked concrete. Construction and Building Materials, 34, 54-62. https://doi.org/10.1016/j.conbuildmat.2012.02.047

\section{General rights}

Copyright and moral rights for the publications made accessible in the public portal are retained by the authors and/or other copyright owners and it is a condition of accessing publications that users recognise and abide by the legal requirements associated with these rights.

- Users may download and print one copy of any publication from the public portal for the purpose of private study or research.

- You may not further distribute the material or use it for any profit-making activity or commercial gain

- You may freely distribute the URL identifying the publication in the public portal 


\title{
Characterization of fracture patterns and hygric properties for moisture flow modelling in cracked concrete
}

\author{
Simon Rouchier ${ }^{\mathrm{a}, \mathrm{b}, *}$, Hans Janssen ${ }^{\mathrm{c}}$, Carsten Rode ${ }^{\mathrm{d}}$, Monika Woloszyn ${ }^{\mathrm{a}, \mathrm{e}}$, Geneviève Foray ${ }^{\mathrm{b}}$, \\ Jean-Jacques Roux ${ }^{a}$ \\ ${ }^{a}$ CETHIL, UMR5008, CNRS, INSA-Lyon, Université de Lyon, Université Lyon 1, Bât. S. Carnot, 9 Rue de la Physique, F-69621 Villeurbanne, France \\ ${ }^{\mathrm{b}}$ INSA-Lyon, MATEIS CNRS UMR5510, F-69621 Villeurbanne, France \\ ${ }^{\mathrm{c}}$ Building Physics Section, Department of Civil Engineering, K.U.Leuven, Kasteelpark Arenberg 40, BE-3001 Leuven, Belgium \\ ${ }^{\mathrm{d}}$ Technical University of Denmark, Department of Civil Engineering, Brovej - Building 118, 2800 Kgs. Lyngby, Denmark \\ e LOCIE, CNRS-UMR5271, Université de Savoie, Campus Scientifique, Savoie Technolac, 73376 Le Bourget-du-Lac Cedex, France
}

\section{A R T I C L E I N F O}

\section{Article history:}

Received 14 October 2011

Received in revised form 7 February 2012

Accepted 25 February 2012

Available online 29 March 2012

\section{Keywords:}

Concrete

Fracture

Digital Image Correlation

X-ray radiography

Moisture transfer modelling

\begin{abstract}
A B S T R A C T
Several years after their installation, building materials such as concrete present signs of ageing in the form of fractures covering a wide range of sizes, from microscopic to macroscopic cracks. All sizes of fractures can have a strong influence on heat and moisture flow in the building envelope, but their distribution is difficult to predict due to the variety of environmental factors which cause them. This paper aims at applying experimental non-destructive techniques for the observation of fracture patterns and of fluid flow in fractures, in order to provide this data to models for fluid transfer in fractured porous media. Digital Image Correlation was performed during the fracturing of concrete samples, in which moisture uptake was then monitored using X-ray radiography. Finite-element simulations were then performed based on the measurements of the fracture patterns, in order to recreate the measured moisture concentration profiles. Digital Image Correlation was found suitable as a mean to obtain a complete mapping of the deformations at the surface of the samples, and a first step was made towards the use of nondestructive fracture characterization for the purpose of moisture transfer modelling.
\end{abstract}

(c) 2012 Elsevier Ltd. All rights reserved.

\section{Introduction}

The hygrothermal performance of porous building materials is now an important issue of building physics. Moisture transfer has a critical influence on the durability and sustainability of built structures, as well as on the health and comfort of their occupants. Any analysis of moisture transfer requires dependable moisture transfer properties, for which various experimental and numerical methods are currently available. However, the understanding of how these properties evolve during the lifespan of building materials is far from complete. The pore structure of the material itself may change over time, or be altered by cracks and defects. Several years after their installation, building materials such as concrete present signs of ageing in the form of fractures covering a wide range of sizes, from microscopic to macroscopic cracks. All sizes of fractures can have a strong impact on heat and moisture flow in the building envelope, and their influence is to be accounted for in any performance assessment, not only of building and build-

\footnotetext{
* Corresponding author at: CETHIL, UMR5008, CNRS, INSA-Lyon, Université de Lyon, Université Lyon 1, Bât. S. Carnot, 9 Rue de la Physique, F-69621 Villeurbanne, France. Tel.: +33 4724384 97; fax: +33472438528.

E-mail address: simon.rouchier@insa-lyon.fr (S. Rouchier).
}

ing components, but of any built structure in general. The infiltration rate of moisture is known to have an important role in the degradation of buildings [1].

Fractures in building materials are caused by a large variety of external factors: mechanical loading, temperature and moisture content fluctuations, infiltration of chemicals such as carbon dioxide causing carbonatation in concrete [2] or chloride ions causing corrosion. An accurate prediction of all ranges of damage in a building component, from microscopic to macroscopic cracks, would either require to include all these effects in a simulation or to assume important simplification hypotheses. This level of complexity being difficult to model, an other approach might be considered when studying the hygrothermal performance of an ageing building component. Fluid flow modelling in a porous medium including a discrete fracture network can be performed following two main methodologies: either by considering an already existing fracture pattern, or by coupling a mechanical model to the fluid flow model. The latter is a coupled mechanical and hygrothermal modelling methodology which consists in predicting the propagation of localized [3,4] or smeared [5] cracks during fluid ingress in the porous medium eventually including poromechanical effects. This allows the study of the mechanical behaviour of the material under hygrothermal influences, but is 
difficult to achieve in the case of building materials due to the complexity of the crack-inducing phenomena. The other option is to run moisture transfer simulations in fractures of known geometry. Setting the crack patterns prior to fluid flow modelling can allow to estimate equivalent properties of the fractured porous network at a higher scale [6], to compare the performance of several modelling methodologies [7] or study the propagation of the crack under hygric influences. The present paper is based on an extension of this approach: the fracture geometries in concrete samples were experimentally characterized before moisture transfer modelling was applied. This method provides the exact distribution of the fracture network without the need for an extensive mechanical modelling and allows estimating the hygrothermal performance of a damaged building component.

The present work serves two main purposes: the first one is to provide experimental measurements of the fracture network inside samples of concrete in order to assemble a complete validation set for 2D models of moisture flow in a fractured heterogeneous porous material. The second purpose is to estimate the ability of non destructive observation techniques to provide the geometrical characteristics of the fractures which may have an influence on the moisture flow.

Digital Image Correlation (DIC) was performed during the fracturing of concrete samples, in which moisture uptake was then monitored with X-ray radiography. Concrete is a composite material made of porous, permeable cement paste binding aggregates of various sizes with very low permeability. Therefore, in such a material, fractures caused by mechanical loading have a tortuous shape and variable aperture due to the presence of aggregates or initially distributed shrinkage cracks. DIC allows to quantify these geometrical characteristics by providing a complete mapping of all displacements at the surface of the sample. The samples are then put in contact with water in order to monitor its infiltration by $\mathrm{X}$-ray radiography inside the characterized fracture network. The resulting moisture concentration profiles serve as a basis for the validation of a finite-element model, which is set to automatically detect the fracture positions from the optical measurements and to simulate moisture flow through the fractured porous material.

The paper is organized as follows: the complete methodology is first entirely outlined starting from the elaboration of the specimen. The experimental and numerical procedure for the quantification of the fracture network, the observation of water infiltration and the moisture transfer modelling in cracked concrete are then described. The outcome of the whole methodology is then displayed and the simulation results are compared to measured moisture profiles.

\section{Methodology}

A formulation of steel fibre reinforced concrete was prepared, based on the proportions shown in Table 1, using Aalborg portland cement with a water to cement ratio of 0.5 . It follows the proportions from previous studies [8] performed at the Technical University of Denmark. The steel fibres have a length of $12.5 \mathrm{~mm}$ and a diameter of $0.4 \mathrm{~mm}$. Their purpose is to allow the interruption of the mechanical loading before complete failure of the specimen, and to ensure their post-crack cohesion in order to use them for subsequent moisture uptake tests.

The mixture is cast in prismatic forms of dimensions $350 \times 100 \times 100 \mathrm{~mm}$, and first wrapped in plastic sheets during $48 \mathrm{~h}$ after casting as to initially maintain a high relative humidity $(\mathrm{RH})$, then stored during 28 days in a stable environment of $50 \%$ $\mathrm{RH}$. After maturation, the edges of the beams were removed since their cement/aggregate ratio is not representative of the average volumetric distributions of the material. Smaller samples of dimensions $140 \times 50 \times 15 \mathrm{~mm}$ were cut out from the beams and notched in their middle as depicted in Fig. 1. The purpose of the notch is to ensure stress concentration and fracture initiation in a concentrated area on which the observation can be focused.

The specimen are loaded by uniaxial tension with a $10 \mathrm{kN}$ force cell imposing a constant longitudinal displacement speed of $0.5 \mathrm{~mm} / \mathrm{min}$ in the direction shown in Fig. 1. A reference picture of the surface is taken with the camera before loading. The tests were then manually interrupted after initiation of a macroscopic fracture. A total of 15 samples was tested and 6 were kept for the moisture uptake measurements.

Fig. 2 shows the response to tensile loading of two specimen of steel fibre reinforced concrete, one of which was fully fractured whereas the other was interrupted before complete failure. The profiles are normalized over their maximal stress and peak displacement. The material shows a quasi-brittle behaviour until its tensile strength is reached. After an important drop in the stress profile indicating fracture initiation, cohesive forces still apply between both sides of the main crack where its aperture is still low [9]. In order to dispose of partially fractured specimen, the tests are interrupted during this stage of the loading, and a second picture of the sample surface is taken with the camera after unloading. This picture is to be used for the image correlation algorithm by comparison with the reference image taken before loading, as explained below. The fractured specimen are then kept in a $45^{\circ} \mathrm{C}$ oven until their water content stabilises at a nearly entirely dry state. Prior to a water uptake test, the sides of each sample were insulated with impermeable tape in order to avoid three-dimensional hygric effects such as evaporation. Their lower side was put in contact with a water surface as shown on Fig. 1 and the upper side was left open as to avoid entrapping of the air initially contained by the porous network as the water front rises inside the sample. The water content distribution was monitored during the uptake by two-dimensional X-ray radiography applied on an observation zone centered on the main fracture originating from the notch.

A finite-element model for moisture transfer is then applied to recreate the moisture distributions measured by X-ray radiography, using the deformations of the specimen measured by image correlation. For the purpose of the modelling procedure, the hygric properties of undamaged concrete have been characterized as well, using dessiccators and pressure plates for the equilibrium moisture content and one-dimensional water uptake monitoring for the permeability of the raw material.

\section{Experimental and numerical procedures}

\subsection{Digital Image Correlation}

Several techniques are available for observing fracture processes in materials such as concrete, each of which has advantages and limitations and offers different opportunities for the interpretations of the results [10]: interferometry, and tomography can reveal existing crack patterns, whereas acoustic emission measurements can be used as a mean to quantify existing or developing damage [11].

Optical techniques such as Digital Image Correlation (DIC) [12] are non-destructive and therefore do not disturb eventual further testing on the samples. DIC provides a full map of the deformations at the surface of a specimen and allows following the fracture development without restriction of number or size of the cracks. It also presents the advantage of being easily implemented into most experimental setups, requiring no strict operating conditions or time consuming preparation, nor does it require gauges in contact with the specimen which might

Table 1

Concrete proportions.

\begin{tabular}{ll} 
Water/cement ratio & 0.5 \\
Cement & $3.465 \mathrm{~kg}$ \\
Sand $0-4 \mathrm{~mm}$ & $8.043 \mathrm{~kg}$ \\
Aggregates $4-8 \mathrm{~mm}$ & $11.580 \mathrm{~kg}$ \\
Steel fibres & $0.2 \mathrm{~kg}$ \\
\hline
\end{tabular}




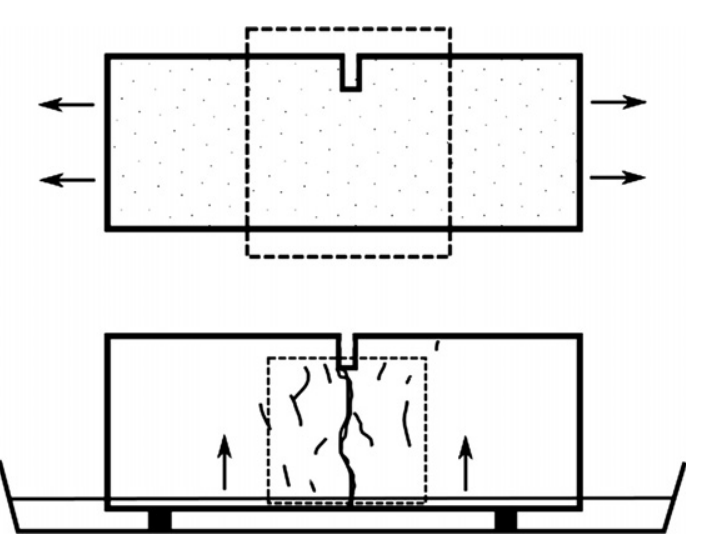

Fig. 1. Setup of the samples during mechanical loading (above) and capillary uptake experiments (below). The arrows respectively show the directions of the tensile loading and moisture uptake, the dotted lines respectively show the DIC and X-ray observation zones.

interfere with the experiment. It is now commonly used for the determination of constitutive laws [13] and has also been applied to the study of the fracture behaviour of concrete $[14,15]$. The principle of DIC is briefly summed up below. For a more complete view of its theory and applications, one can refer to a recent book on the subject [16].

\subsubsection{Principle}

The principle of Digital Image Correlation is the conservation of the optical flow between two pictures of a specimen, taken at different stages of its deformation. The planar displacement $u(x)$ at each point $x$ of a surface is defined as:

$g(x+u)=f(x)$

where $f$ is a reference image, typically taken at the start of the mechanical loading, and $g$ a deformed image. The target is to determine the best possible approximation for $u$ by minimizing the error between $u$ and an approximation $v$. This is done by searching the minimum value for the functional $\phi$ defined as:

$\phi(v)=\iint(g(v+x)-f(x))^{2} \mathrm{~d} x$

Assuming a certain smoothness of the investigated displacement field, $g$ is replaced by its first-order Taylor expansion in Eq. (1) and $v$ is decomposed into a linear combination of functions

$v(x)=\sum N_{i}(x) v_{i}$

$\left[\int(\nabla g(v+x) \otimes \nabla g(v+x)):\left(N_{j} \otimes N_{i}\right) \mathrm{d} x\right] v_{i}=\iint(f(x)-g(x)) \nabla g(x) N_{i}(x) \mathrm{d} x$

Since $f, g$ and $N_{i}(x)$ are known, Eq. (3) is a linear system of unknown $v_{i}$, from which the approximate displacement field $v$ can be obtained. Understandably, the choice of the basis functions $N_{i}(x)$ is important for a good approximation of the displacement field, and several options have been presented in the literature for different types of mechanical tests. In the present case, the computation of the displacements is achieved with the Icasoft software, ${ }^{1}$ which uses bilinear finite element shape functions. The displacement field is analysed by dividing the image into grid elements, each of which is assigned two displacement components in the decomposition of Eq. (2). The result of Eq. (3) is a rough estimate of the real solution, since it only computes an integer number of pixels for the displacement fields. Subpixel interpolation algorithms are then implemented for finer results.

The result of the algorithm is an approximation of the displacement field $u$ of each point of the surface. While gradients of $u$ define the strain fields, a sharp difference in the displacement of two adjacent points indicate a crack.

\subsubsection{Settings}

The samples are observed during tensile loading with a camera focused on the surrounding of the notch as shown in Fig. 1. The setup uses a $50 \mathrm{~mm}$ fixed focal macro lens with a 2.8 focal ratio. Because of the low depth of field of the camera in this configuration, the focus is manually fixed as to prevent an automatic adjustment of the lens during the tests. Depending on the distance between the specimen and the camera, the spatial resolution varies from 10 to $20 \mu \mathrm{m} /$ pixel. The observation zone is extracted from larger images of $3057 \times 4592$ pixels, in order to cover for a possible translation of the sample during loading. In order to facilitate the pro-

\footnotetext{
${ }^{1}$ Icasoft Digital Image Correlation Software - http://icasoft.insa-lyon.fr/.
}

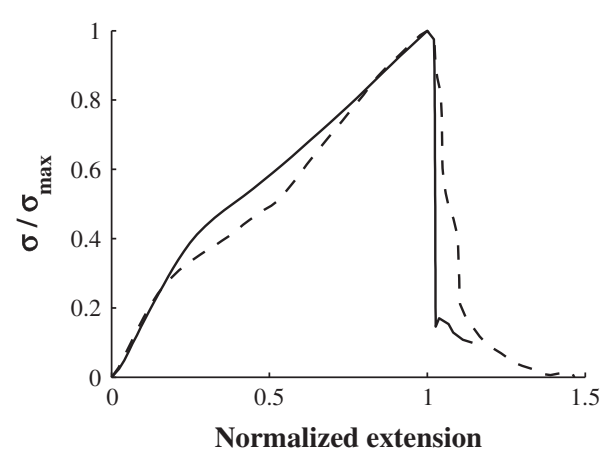

Fig. 2. Complete (dotted line) and interrupted (continuous line) tensile loading profile of steel fibre reinforced concrete.

cedure of the correlation algorithm, a speckle pattern was applied on the surface of the specimen with a black paint spray. A grid of $8 \times 8$ pixel elements is used for the calculation.

\subsection{X-ray radiography}

The observation of the two-dimensional moisture concentration distributions in porous building materials is now a common procedure in the characterization of their hygric properties. This can be done using gravimetric methods [17] or techniques such as nuclear magnetic resonance, $\gamma$-ray attenuation, capacitance method or X-ray projection [2]. Several purposes can be served by these methods: extrapolation of the liquid conductivity from transient one-dimensional moisture uptake tests [18], observation of local variations of the flow speed due to fractures [19] or of the infiltration of chemicals, studies of reinforcement corrosion in concrete [8], etc. In the recent years, these techniques have been increasingly used in material sciences, and new operating methods were presented for their optimization and for a more efficient interpretation of their results.

\subsubsection{Principle}

The principle of X-ray radiography is to measure the attenuation of an X-ray photon beam through a specimen. A camera placed on the other side of the specimen detects the amount of transmitted photons, which in the case of building materials allows measuring the concentration of water or other chemicals. If the intensity of the source is denoted $I_{0}$, the intensity $I$ transmitted by a sample of thickness $d$ is expressed by Beer's law:

$I=I_{0} \exp (-\mu d)$

where $\mu$ is the attenuation coefficient of the material. This coefficient indicates the probability of a photon to interact with the material (and to not reach the camera) per unit length. It is a function of the photon energy, the density and effective atomic number of the material. In case of a moisture uptake experiment, the local water concentration inside a specimen can be considered as an additional layer of thickness $d_{w}$ and attenuation coefficient $\mu_{w}$. The measured intensity from a wet sample $I_{\text {wet }}$ can then be expressed as separately attenuated by the dry material and this water layer.

$I_{\text {wet }}=I_{d r y} \exp \left(-\mu_{w} d_{w}\right)=I_{0} \exp \left(-\mu d-\mu_{w} d_{w}\right)$

The moisture content $w$ is related to this fictitious moisture thickness by:

$w=\frac{\rho_{w} d_{w}}{d}$

The water concentration inside the porous medium can therefore be obtained from the intensities measured through the material before and after its contact with the water:

$\Delta w=-\frac{\rho_{w}}{\mu_{w} d} \ln \left(\frac{I_{w e t}}{I_{d r y}}\right)$

where $\Delta w$ is the increase in water content from the initial state, which is not necessarily entirely dry. The linear attenuation coefficient of water is considered unknown at first and will be determined by coinciding the X-ray intensity transmitted by a water-saturated concrete sample with the measured capillary moisture content. The procedure of the experiment is as follows: the sample is initially placed in a container and a first image is taken to measure the dry intensity $I_{d r y}$. Water is then poured in the container as to be in contact with the bottom surface of the sample. Measurements of intensity transmitted by the wet material $I_{\text {wet }}$ follow regularly as the moisture front rises inside the material.

According to Eq. (7), the result $w$ shown at one location of the two-dimensional plane of observation is the average of the water mass per volume over the thickness of the sample. If the material is considered homogeneous in comparison with its 
dimensions and the size of the observation zone, $w$ will reach a homogeneous distribution at saturation. However, concrete is a highly heterogeneous material, and the specimen of the study have a thickness of only a few times the size of the largest aggregates. The assumption of homogeneity can therefore not be made here. Aggregates have a much lower equilibrium moisture content than cement paste, and the observation of the local water concentration does not depict the actual wetting state of a specimen correctly. This is corrected for by considering the non-dimensional water content $s$, or saturation degree of the liquid phase:

$s=\frac{\ln \left(I_{\text {wet }} / I_{\text {dry }}\right)}{\ln \left(I_{\text {sat }} / I_{d r y}\right)}$

where $I_{\text {sat }}$ is the recorded intensity transmitted by a capillary saturated sample. This definition implies that a series of measurements must be carried on until saturation of the specimen in order to normalize the water content between an initial and a final state.

\subsubsection{Settings}

The moisture profile tests were performed with the GNI X-ray system at the Department of Civil Engineering of the Technical University of Denmark.

The intensities are recorded as 16-bit images showing up to 65535 greyscale levels. The size of each image is $252 \times 256$ pixels covering an area of $12 \times 12 \mathrm{~mm}$, i.e. with a pixel size of $50 \mu \mathrm{m}$. The X-ray source and the camera can be displaced following a pre-programmed path, which allows the user to visualise larger areas by assembling images taken at several adjacent locations. In this study, the entire observation zone for each series of measurements covers a rectangle area of $3 \times 3$ images (or $3 \times 4$ images for observation of uncracked samples, as explained below), positioned so that the main fracture of the specimen is slightly away from the center (see Fig. 1). This setup allows including the entire height of the sample between the water front and the notch, and to cover a large enough area in orde to capture the evolution of the water front within several hours of measurements.

Since non-negligible fluctuations in the intensity of the X-ray source are expected during the measurements, each image of the assembling is the averaged intensity measured over 40 pictures of the same location, each of which taken with a camera integration time of $1500 \mathrm{~ms}$. The entire acquisition of the observation area, including the time of displacement of the camera and source between the locations, lasts around $10 \mathrm{~min}$. Such a time interval between the first and the las images of a series is not problematic here because of the low permeability of concrete, and all images can be considered taken at the same time. The Image J software $^{2}$ is used for the assembling of all images.

The energy of the X-ray source is set as to ensure a good resolution of the water content profiles. According to [19], the resolution of moisture content $R_{w}$ is defined as one greyscale step of an image and is mainly a function of the sample thickness for each type of material.

$R_{w}=-\frac{\rho_{w}}{\mu_{w} d} \ln \left(\frac{I_{d r y}-1}{I_{d r y}}\right)$

The drawback of a high energy is a possible instability of the source which as a consequence would make longer integration times necessary. A fair compromise was found at $E=85 \mathrm{keV}$, which coincides with the energy suggested by [19] for ceramic brick samples of similar $15 \mathrm{~mm}$ thickness. This results in an average resolution of $R_{w}<0.5 \mathrm{~kg} \mathrm{~m}^{-3}$.

\subsection{Moisture transfer modelling in concrete}

After the observation of moisture concentration profiles within the fractured samples, a first attempt to implement DIC results into a code for moisture transfer simulations was made. The first step into this procedure is the hygric characterization of concrete. This data was then implemented into a finite element model which was programmed to automatically detect fractures and to run two-dimensional transient moisture transfer simulations on this domain.

\subsubsection{Basic concepts}

The two-dimensional conservation equation for isothermal moisture transfer in building materials is written with the capillary pressure as driving potential:

$\frac{\partial w}{\partial p_{c}} \frac{\partial p_{c}}{\partial t}=\nabla \cdot\left(K_{w} \nabla p_{c}\right)$

The right side of the equation is often split in two terms, one describing liquid moisture transfer driven by capillary forces and one describing water vapour diffusion in the gaseous phase. In the present case however, both phases are described by a total permeability of the material $K_{w}$. The left side of the equation indicates the storage of moisture in the pore structure and is described by the moisture retention curve, i.e. the equilibrium moisture content of the material $w$ versus relative humidity or capillary pressure $p_{c}$.

The full hygric characterization of porous building materials includes measurements of these storage and transport properties, in both hygroscopic and over-

\footnotetext{
2 Image image processing and analysis in Java, www.rsbweb.nih.gov/ij/.
}

hygroscopic ranges. In the hygroscopic range, moisture transfer mostly occurs through diffusion or advection phenomena of water in the gaseous phase. The over-hygroscopic range represents higher concentrations of water in the material, where transfer in the liquid phase prevails. The transport and equilibrium properties of concrete are to be measured during wetting, as opposed to previous studies concerning the drying of several formulations of concretes and cement pastes [20].

The procedures for experimental characterization of storage and transport properties are explained below: the moisture retention curve was characterized by weighing samples placed in stable humidity conditions. The permeability was measured following the Boltzmann technique [18], which requires the monitoring of moisture concentration distributions in the material during capillary uptake.

\subsubsection{Hygric characterization}

The complete profile of moisture content $w$ versus capillary pressure $p_{c}$ was measured using two separate methods in order to cover the entire humidity range: dessiccators were used in the hygroscopic range between $11 \%$ and $97 \%$ relative humidity $\left(p_{c}>4 \times 10^{6} \mathrm{~Pa}\right)$ and pressure plates were used in the over-hygroscopic range $\left(p_{c}<4 \times 10^{6} \mathrm{~Pa}\right)$. The samples used for the dessiccator method are initially oven-dried, whereas the pressure plate method proceeds by extracting water from initially vacuum-saturated samples. Therefore, the former method provides the sorption curve for the hygroscopic range, while the latter provides the desorption curve for the over-hygroscopic range. This was corrected for by subtracting the recorded difference between capillary and vacuum saturation contents to the desorption (extractors) measurements. This difference being relatively low, the assumption could be made that the result is a full sorption curve.

Aside from the observations of water infiltration in cracks, the X-ray equipment was also used to monitor moisture uptake in uncracked samples of concrete. Transport properties can either be characterized by means of a water absorption coefficient estimated by weighing samples during free water uptake experiments $[21,22]$, or by monitoring concentration profiles in the samples. The latter approach allows characterizing the entire profile of unsaturated moisture permeability. In order to estimate the moisture transport properties of the material, let us consider a simplified formulation of Eq. (10) for the case of one-dimensional moisture transfer with $w$ as the driving potential (note: in the present case, moisture transfer occurs in the vertical direction $y$ ):

$\frac{\partial w}{\partial t}=\frac{\partial}{\partial y}\left(D_{w} \frac{\partial w}{\partial y}\right)$

where $D_{w}$ is the moisture diffusivity. As explained in [18], $D_{w}$ can be derived from transient 1D moisture profile measurements through a Boltzmann transform $\lambda=y t^{-1 / 2}$

$D_{w}=-\frac{1}{2} \frac{\int_{0}^{w} \lambda \mathrm{d} w}{\partial w / \partial \lambda}$

The one-dimensional moisture profiles were monitored in a non-damaged concrete sample by X-ray radiography. Several consecutive measurements of the vertical distribution of the moisture content $w$ were performed during a water uptake test and superimposed as to obtain a single humidity profile. The moisture diffusivity is calculated from the resulting mean moisture concentration profile using Eq. (12). The permeability was then derived following its definition:

$K_{w}=D_{w} \frac{\partial w}{\partial p_{c}}$

where $\partial w / \partial p_{c}$ is the slope of the moisture retention curve. The calculation of $K_{w}$ therefore requires the knowledge of both the equilibrium moisture content and the moisture diffusivity. One of the main advantages of the Boltzmann method to derive the transport properties of a material is the fact that the term $K_{w}$ includes moisture transport in both liquid and gaseous phases.

\subsubsection{Modelling settings}

Simulations were run using a new model currently under development, which aims at including experimental observations of the fracture network geometries into heat and moisture simulations. The present work aims at recreating isothermal moisture flow from the main fracture through the surrounding porous material.

Eq. (10) was discretised over a triangular finite-element mesh using the Galerkin weighted-residual method, implicit temporal discretisation and a NewtonRaphson iterative scheme. The complete procedure for numerical implementation of Eq. (10) is explained in [23]. As a first use of the model, the fractures in contact with the water front will be considered initially water-filled before starting the simulations. This is consistent with observations and previous simulations [24] of these fractures filling within seconds after contact of the sample with water, and with the fact that concrete has a low permeability in comparison to other building materials such as brick or sandstone. This hypothesis implies that the fracture is considered a hydraulic continuity, as opposed to other existing contact configurations [25]. The model will be extended in upcoming works as to account for fracture flow and imperfect hydraulic contact between crack sides.

A first non-structured mesh was generated on the domain where the surface displacement fields have been measured by DIC. The correlation results were then interpolated at the node coordinates of the finite element mesh. If two adjacent 
nodes show an important difference in displacement, their support is considered crossed by a fracture and an additional node was inserted. The domain is then remeshed including the new nodes. While simulating a moisture uptake test as displayed on Fig. 1, these fracture nodes and the lower boundary of the domain are implemented with a Dirichlet boundary condition (constant capillary pressure) to indicate water saturation at these locations.

\section{Results and discussion}

The results of the experimental and numerical procedure are now displayed and discussed. As a first step, the results of the fracture characterization by Digital Image Correlation are displayed as to determine whether this technique can provide a satisfactory observation of the crack patterns within the material. The resulting cartographies of deformations are then superimposed to the moisture profiles obtained by X-ray radiography in order to estimate the reliability of non-destructive fracture characterization as a mean to predict moisture infiltration. The characterized transport and storage moisture properties of concrete are then displayed as a basis for the upcoming transfer modelling. Finally, the simulation results are shown and confronted to moisture ingress measurements by X-ray in the fractured porous material. All data presented in the present section concerns the same sample of concrete, whereas numerical data is provided in Appendix A concerning the crack geometry of a second sample.

\subsection{Observation of fracture patterns}

The DIC algorithm works by comparing a reference picture of the surface of a specimen taken before loading, and a deformed picture taken after unloading (see Fig. 3a). The result of the calculation is the displacement field in the direction of the loading. It is shown in the form of contour lines on Fig. 3b, each one representing a difference of $5 \mu \mathrm{m}$ of the displacement field in the $x$ (horizontal) direction. A local concentration of the contour lines indicates a steep local difference in the displacement, and therefore locates a fracture.

The mechanical loading of the sample was interrupted before its entire failure. The main fracture can be seen on Fig. 3a originating from the notch in the middle of the upper boundary, and propagating downwards. This crack presents a tortuous shape and secondary discontinuities can be seen propagating from it, mostly along the cement/aggregate interfaces. The horizontal contour lines on both sides of the main crack do not indicate the presence of fractures, but are caused by the notch on the upper side of the sample: as the crack expands, both sides of the sample tend to slightly

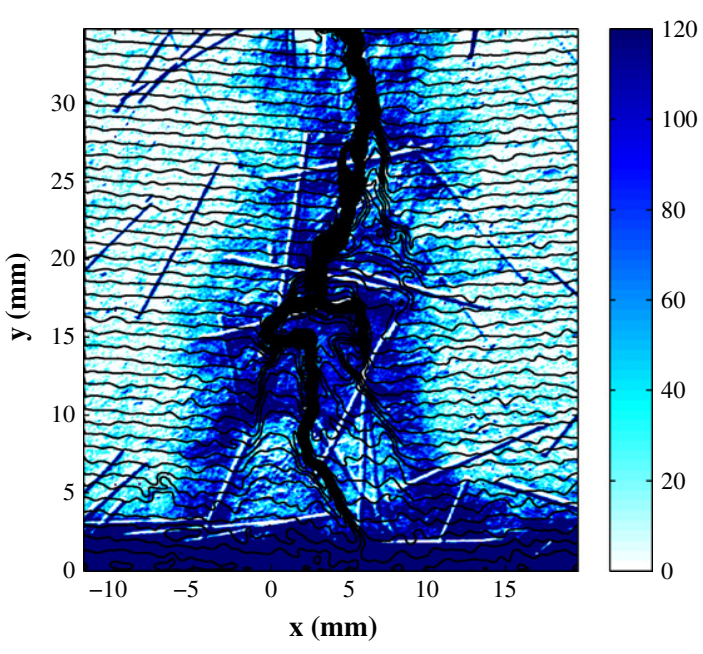

Fig. 4. Water content distribution $10 \mathrm{~min}$ after wetting $\left(\mathrm{kg} \mathrm{m}^{-3}\right)$ and sample deformation contour lines $\left(5 \times 10^{-6} \mathrm{~m} /\right.$ line $)$.

rotate around the third axis in opposite directions, causing a gradient of horizontal displacement along the vertical coordinate. With further loading, the main fracture (shown by the higher concentration of contour lines) expands and tends to cause the surrounding cracks to close. It can therefore be expected that the moisture content distributions observed during water uptake tests will be influenced by the state of the sample when mechanical loading is interrupted.

From the results shown on Fig. 3b, it can be seen that with the present settings, Digital Image Correlation is able to detect cracks of down to $10 \mu \mathrm{m}$ aperture on a relatively large area of observation. In terms of spatial resolution, other techniques such as electronic speckle pattern interferometry or micro-tomography have been found to detect cracks of under $1 \mu \mathrm{m}$ opening [10]. The spatial resolution of DIC is mostly a matter of the physical pixel size, i.e. of the settings of the camera (spatial position, focal length). A compromise must be found between searching for smaller crack apertures and covering a large enough observation area.

The technique also provides the shape and tortuosity of all fractures, as well as the local variations of their aperture. All of these parameters are likely to have an influence on the moisture flow inside the fractures [26] and in the surrounding porous material. DIC therefore has the potential to be a significant improvement to the
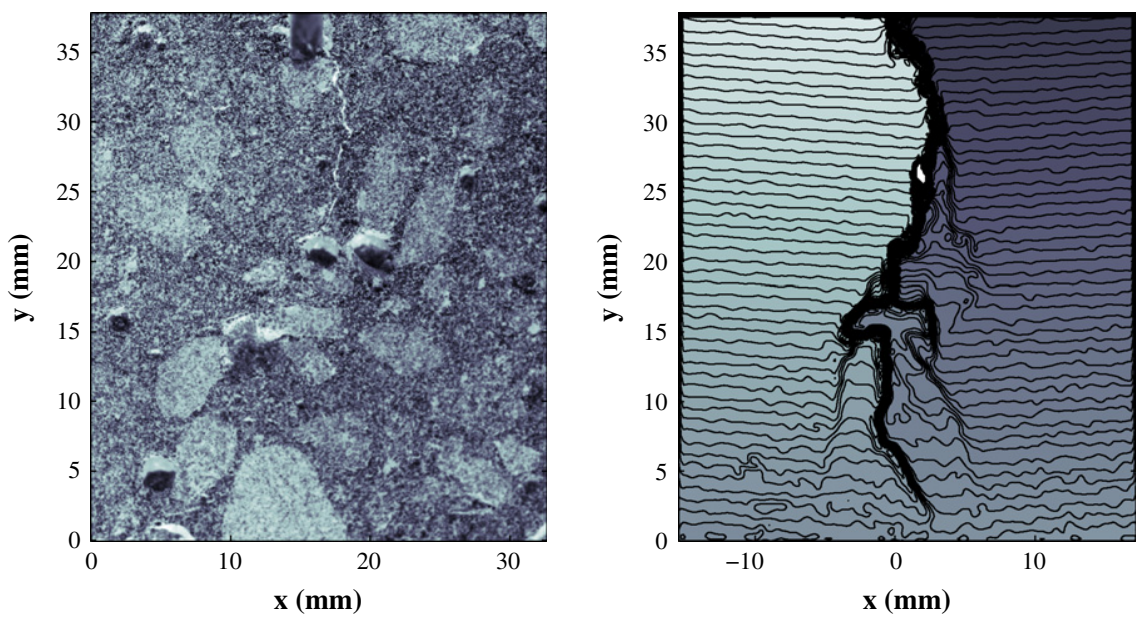

Fig. 3. (a) Picture of a specimen surface after mechanical loading. (b) Surface displacement mapping of a concrete sample from Digital Image Correlation (5 $\mu$ m/line). 


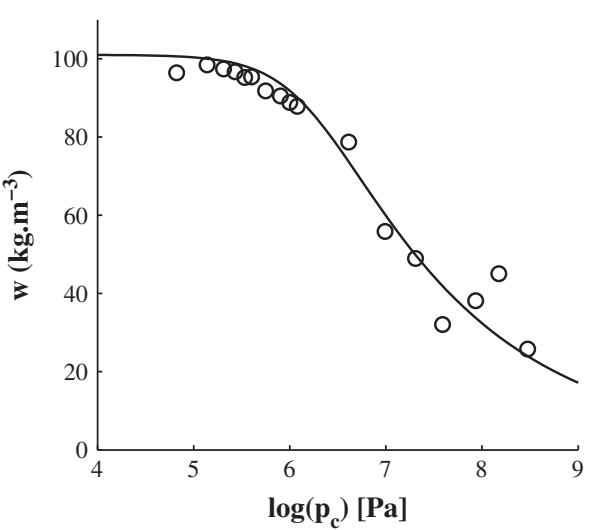

Fig. 5. Moisture retention curve measurements versus capillary pressure (circles) and approximation by van Genuchten model.

Table 2

Coefficients of the sorption isotherm approximation for concrete.

\begin{tabular}{llll}
\hline$m$ & $n$ & $\alpha\left(\mathrm{Pa}^{-1}\right)$ & $w_{\text {sat }}\left(\mathrm{kg} \mathrm{m}^{-3}\right)$ \\
\hline 0.2191 & 1.2566 & $6.165 \times 10^{-7}$ & 101.44 \\
\hline
\end{tabular}

moisture flow prediction in comparison to an arbitrary choice of the fracture geometry.

DIC has two main downsides when applied to the localization of fractures for flow simulations: first, since it is a mapping of the surface of the samples, the discontinuities appearing within the volume of the material do not show on the results. As a consequence, subsequent water infiltration may follow paths which are not captured by the technique. This issue can be corrected by considering samples of relatively low thickness, in which most discontinuities are expected to show on the sample surface. This will be discussed in the next section. The second downside of the technique is the fact that DIC must be applied while deformations occur, since a reference picture of the sample is required for the calculations. This prevents its applicability to in situ characterization of building components. This matter will be discussed in the conclusion of the paper.

\subsection{Superposition of DIC and X-ray measurements}

As explained above, each moisture content distribution provided by the equipment is an assembling of pictures taken at several locations, each of which is the average intensity measured during $60 \mathrm{~s}$ of integration. During the earliest stage of wetting, water movement near the water front and inside the fracture is fast in comparison with the time needed for measuring. Therefore, in order to be able to consider an assembling of pictures as coming from one single time coordinate, the first moisture content distribution within each specimen was measured around 8 min after contact with water. The result is shown on Fig. 4 for the sample shown above on Fig. 3.

The bottom of the image show the water meniscus in contact with the specimen. The $x$-axis was centered on the position of the notch. The water content is depicted by the color mapping, while the fractures and deformations are shown by the contour lines as previously depicted. The following observations can be deduced from the example shown on Fig. 4: first, the moisture concentration profiles on the early stages of wetting follow the shape of the main cracks observed with Digital Image Correlation, which are visible as the highest concentration of contour lines. Fractures under $100 \mu \mathrm{m}$ aperture also contribute significantly to the flow, as shown by the smaller fractures which are quickly filled with water as well. However, in some cases, water can take additional paths which have not been captured by DIC. As mentioned above, this observation technique only captures deformation processes appearing on the surface of the sample, and not all cracks opening within the volume of the material are visible.

These observations underline the applicability of DIC as a mean to predict preferential moisture paths, but also show its limitations. The next part of the results handles the observation and modelling of the moisture flow outside of the fracture.

\subsection{Hygric characterization}

The sorption isotherm was measured with dessiccators and pressure plates as described above. In order to interpolate the profile to the entire range of capillary pressure, the results are approximated with a van Genuchten function [27]:

$w\left(p_{c}\right)=w_{\text {sat }}\left[1+\left(\alpha\left|p_{c}\right|\right)^{n}\right]^{-m}$

where the parameters $m, n, \alpha$ are determined by approximation of the measured equilibrium moisture contents. The results of this process are shown on Fig. 5 and Table 2.

X-ray radiography was then used to observe capillary moisture uptake in an undamaged concrete sample. Fig. 6a was obtained by stacking six consecutive moisture profile measurements, performed between 100 and $400 \mathrm{~min}$ after wetting of the sample. It can be seen that the data is quite scattered due to the heterogeneity of the material, but the distributions globally coincide. All profiles are then assembled as one average distribution, which is then smoothed and approached by a cubic spline interpolation.

As stated in [18], a boundary moisture content $w_{B}$ must be assigned at the inflow surface in order to satisfy the Boltzmann boundary conditions. This value can be considered equal to the
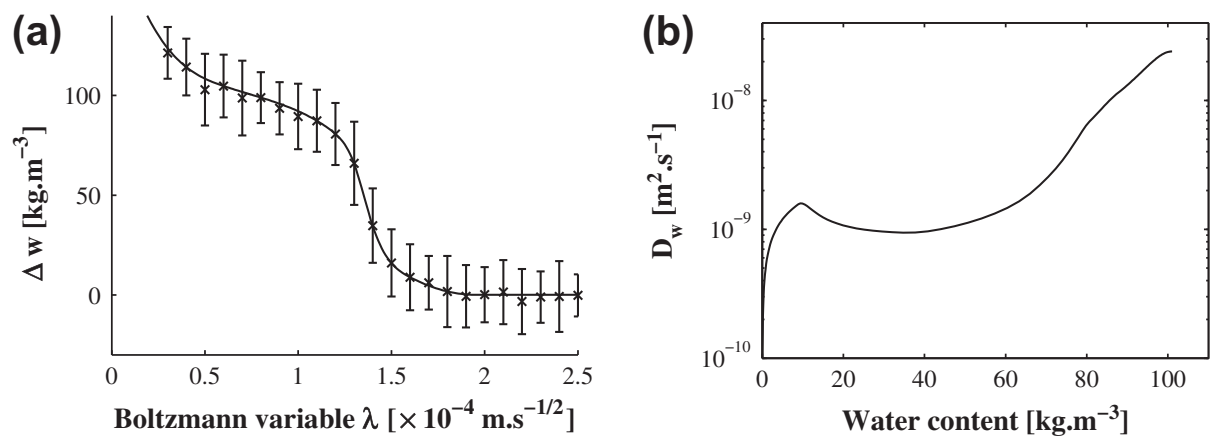

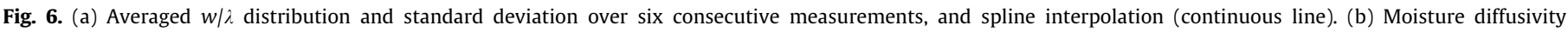
extrapolated from transient measurements. 
Table 3

Coefficients of the multi-modal approximation of the moisture permeability profile.

\begin{tabular}{llllll}
\hline$m$ & $n$ & $\alpha\left(\mathrm{Pa}^{-1}\right)$ & $l$ & $K_{\text {sat }}(\mathrm{s})$ & $\tau$ \\
\hline 0.6148 & 2.5963 & $5.5383 \times 10^{-7}$ & 0.5062 & $2.2182 \times 10^{-13}$ & -4.6975 \\
0.1913 & 1.2366 & $2.2493 \times 10^{-8}$ & 0.4938 & & \\
\hline
\end{tabular}

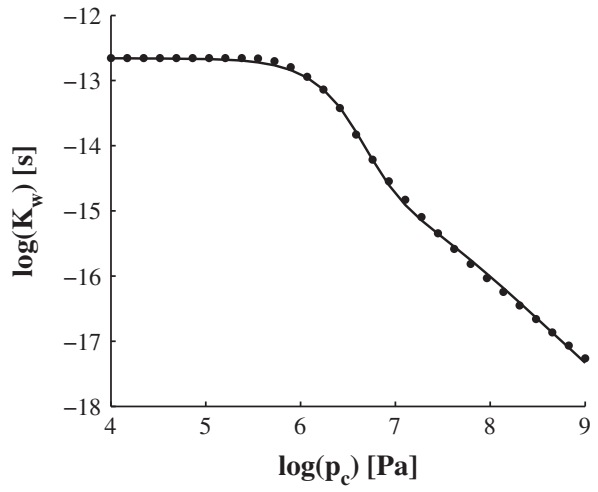

Fig. 7. Moisture permeability from measurements (dots) and Durner model (line) versus capillary pressure.

capillary moisture content of the material, i.e. the maximal moisture concentration $w_{\text {sat }}$ reachable by water uptake under atmospheric pressure. Under this assumption, the moisture diffu-

sivity $D_{w}$ was calculated as follows: first, $D_{w}$ was computed using Eq. (12) from one-dimensional concentration profiles based on an arbitrary value of the photon attenuation coefficient of water $\mu_{w}$ The diffusivity profile showed a maximum value where the boundary moisture content $w_{B}$ is supposed to be reached. The attenuation coefficient was then arranged so that $w_{B}$ matches the known value of the capillary saturation content $w_{s a t}$, which results in a value of $\mu_{w}=17.12 \mathrm{~m}^{-1}$.

The resulting diffusivity profile shown on Fig. $6 \mathrm{~b}$ is used to calculate the permeability through Eq. (13), which was then approximated by a multi-modal Durner function [28]:

$K_{w}=K_{\text {sat }} s^{\tau}\left[\frac{\sum_{i} l_{i} \alpha_{i}\left(1-\left(1-s_{i}^{1 / m_{i}}\right)^{m_{i}}\right)}{\sum_{i} l_{i} \alpha_{i}}\right]^{2}$

where $K_{\text {sat }}$ is the saturated permeability. In this expression, the retention function $s$ is divided into subcurves $s_{i}$, each one representing a pore size subsystem:

$s=\sum_{i} l_{i} s_{i}=\sum_{i} l_{i}\left[1+\left(\alpha_{i}\left|p_{c}\right|\right)^{n_{i}}\right]^{-m_{i}}$

The parameters $l_{i}, \alpha_{i}, m_{i}, n_{i}$ estimated by approximation of expression (15) with the experimental results do not necessarily have the same values as those obtained from the retention curve (see Table 2). In the present study, a better fit of the permeability profile was reached with the parameters displayed in Table 3, as shown on Fig. 7.
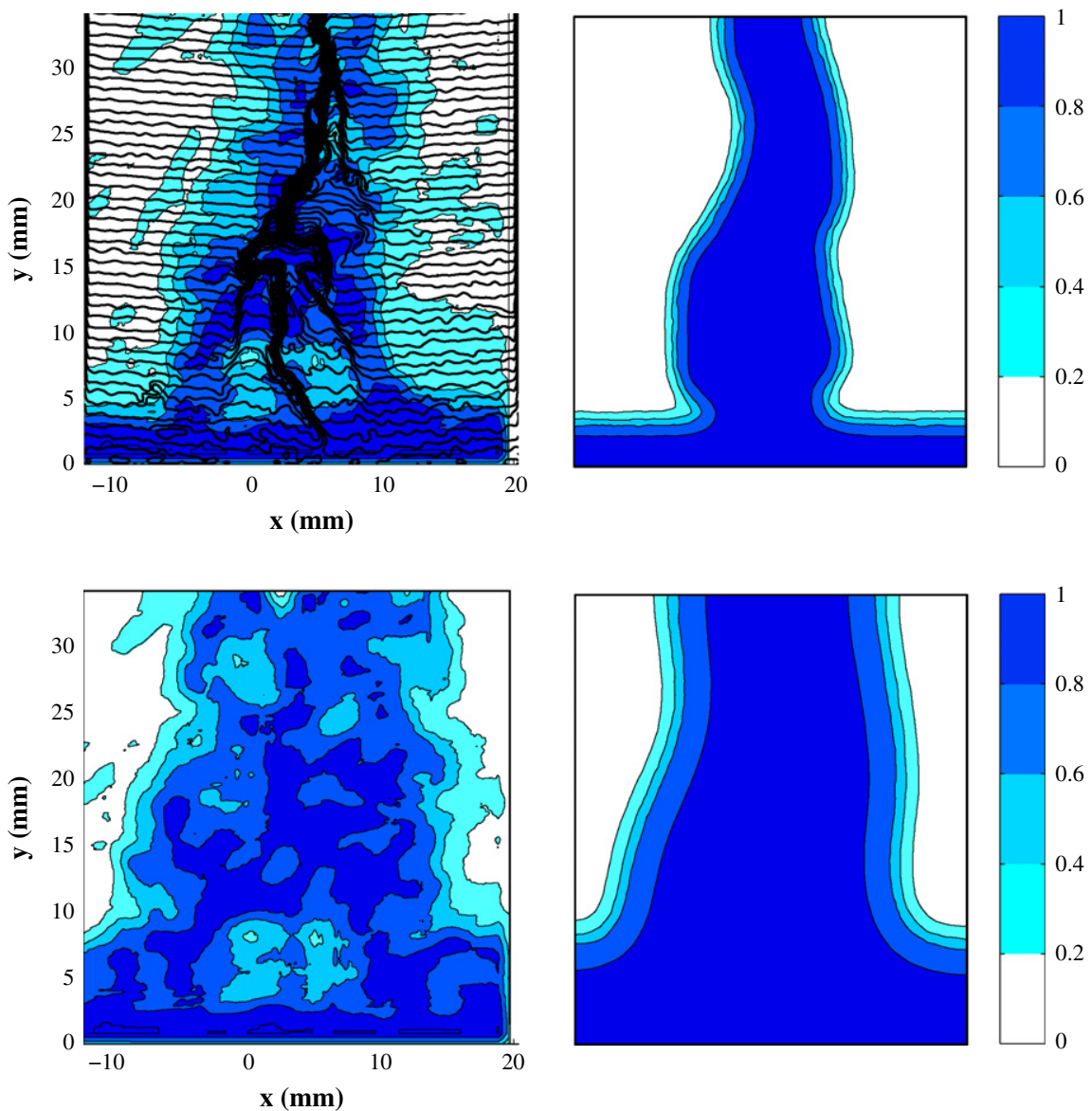

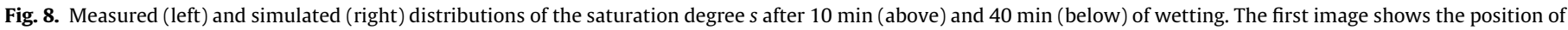
the cracks captured by DIC. 


\subsection{Moisture transfer modelling and monitoring}

As stated above, the depiction of the wetting state of the material by the water content $w$ is not always appropriate due to the high heterogeneity of the material. Fig. 4 shows local fluctuations of the water content which are not only due to the presence of cracks, but also to the distribution of aggregates and cement paste. In order to reveal a moisture front and attempt to measure its advance, the non-dimensional moisture content $s$ is now considered (see Eq. (8)).

Due to the low permeability of concrete, the water concentration distributions were both measured and simulated over several hours after contact of the sample with the water front. The simulations are based on a grid of $0.7 \mathrm{~mm}$ triangular elements, with time steps of $2 \mathrm{~min}$. In order to account for the initially nearly dry state of the material, the capillary pressure at $t=0$ is set to $p_{c}=-5 \times 10^{8} \mathrm{~Pa}$.

The comparative results of the moisture concentration monitoring and modelling are shown on Fig. 8 as two consecutive measurements of the saturation distributions for the same sample. The displacement field at the surface of the sample is shown as contour lines on the upper left image. The simulations show a fair accuracy in the shape and evolution of the moisture fronts from the bottom water surface and from the fractures. This confirms the relevance of the hypothesis of initially water-filled fractures.

At earlier stages of wetting, it is visible on both simulations and experiments that the shape and tortuosity of the cracks has a noticeable impact on the shape of the moisture fronts (Fig. 8a and b). The crack width shows no noticeable impact on the moisture flow in the neighbouring porous material: because concrete has a low permeability, the flow inside the fracture occurs at a much smaller time scale than through the porous network. Therefore, the moisture saturation of a water-filled crack does not appear affected by the migration of moisture through its walls to

Table A.4

Position and aperture of the main crack in the second reference sample.

\begin{tabular}{rll}
\hline$x(\mathrm{~mm})$ & $y(\mathrm{~mm})$ & $a\left(\times 10^{-4} \mathrm{~m}\right)$ \\
\hline-3.3042 & 0 & 1.4889 \\
-3.6836 & 1.2236 & 2.7256 \\
-3.4596 & 2.4471 & 2.8292 \\
-3.5335 & 3.6707 & 2.7422 \\
-3.2970 & 4.8943 & 2.9217 \\
-3.1608 & 6.1179 & 3.0143 \\
-3.0388 & 7.3414 & 2.8012 \\
-2.1352 & 8.5650 & 2.7121 \\
-2.1257 & 9.7886 & 2.6523 \\
-1.0648 & 11.0122 & 2.4571 \\
-0.9687 & 12.2357 & 1.7370 \\
0.6810 & 13.4593 & 3.0582 \\
1.2109 & 14.6829 & 2.8954 \\
0.8548 & 15.9065 & 2.8565 \\
1.6427 & 17.1300 & 2.7664 \\
2.0858 & 18.3536 & 2.9611 \\
2.2049 & 19.5772 & 2.8261 \\
1.9665 & 20.8008 & 2.8060 \\
1.2050 & 22.0243 & 2.8996 \\
0.9245 & 23.2479 & 3.0533 \\
0.9347 & 24.4715 & 2.9321 \\
1.4069 & 25.6951 & 2.9470 \\
0.9609 & 26.9186 & 2.8931 \\
0.0112 & 28.1422 & 2.9744 \\
-0.1474 & 29.3658 & 3.0566 \\
-0.2061 & 30.5894 & 3.0740 \\
0.1037 & 31.8129 & 1.9138 \\
-0.0044 & 33.0365 & 2.9545 \\
1.1235 & 34.2601 & 2.4714 \\
0.5347 & 35.4837 & \\
\hline & & \\
\hline
\end{tabular}

the porous network. This effect is likely to not be valid for other building materials with higher permeability such as brick or gypsum boards, making it necessary to include a fracture flow model in the simulations.

Under atmospheric conditions, the eventual contact of a liquid water phase with a side of a building component is caused by wind-driven rain $[29,30]$. The water flow at the surface is then no longer comparable to a continuous water front and the fracture is likely to present a variable moisture content. Under these conditions, a fracture flow model is necessary as well, for which the complete fracture geometry provided by DIC can be an important input as it includes the distributions and variable apertures of the cracks. This underlines the importance of the present experimental and numerical methodology, and shows the necessity of extending the current modelling procedure to include flow within the fractures.

\section{Conclusion}

Cracked samples of concrete have been submitted to moisture uptake measurements by X-ray radiography, after their fracture patterns were observed by Digital Image Correlation. The target was to evaluate the ability of DIC to provide a reliable characterization of the fracture geometries in order to predict moisture uptake through a damaged porous material.

It was established that DIC is a reliable non-destructive technique which can provide accurate quantitative measurements of the fracture patterns: microcracks of down to $10 \mu \mathrm{m}$ aperture were observed on a relatively large area. The overall shape, tortuosity and variable aperture of the surface fractures can be accurately captured. The technique is however limited to a two-dimensional observation of the surface of a thin sample, which prevents its implementation to the case of relatively larger building components, in which fractures might propagate without appearing on the monitored surface.

Moisture uptake was monitored as to confirm the ability of computer vision to predict the moisture uptake paths in the earlier stages of wetting. The water infiltration from the fractures to the surrounding porous material was then observed. These moisture content profiles were then approached by finite-element moisture uptake modelling based on the measurements of deformation fields at the surface of the samples. The two-dimensional infiltration of water from a water-filled fractured could be recreated similarly to the experimental observations.

The in situ hygrothermal characterization of damaged building materials can follow the same procedure, by replacing the DIC results by an other similar non-destructive technique for fracture localization. Further work is to be performed as to investigate the ability of such techniques to provide three-dimensional crack geometries in existing building components. The moisture flow modelling is to be improved as well, as to include the possibility of simulations under climatic conditions of fractured porous media.

\section{Acknowledgements}

The results presented in this paper have been obtained during the Renovbat project for the study of flow in fractured building components. Funding was provided by the Energy research cluster of the Rhône-Alpes region, which the authors would like to thank for their financial support through the project.

The authors would also like to thank K.K. Hansen and the researchers of the Construction Materials section of the Civil Engineering Department at the Technical University of Denmark for their help in the experimental processes. 


\section{Appendix A. Fracture geometry}

In order to provide a "real" two-dimensional fracture geometry for fracture flow simulations, numerical data is provided here. This data concerns a sample showing a single tortuous macroscopic crack and no microscopic side cracks. A fair approximation of its trajectory can be reached by cubic spline interpolation between the points listed in Table A.4. The table also lists the fracture aperture at each of these points.

\section{References}

[1] Torres I, de Freitas VP. The influence of the thickness of the walls and their properties on the treatment of rising damp in historic buildings. Constr Build Mater 2010;24:1331-9.

[2] Černý R, Rovnaníková P. Transport processes in concrete. London: Spon Press; 2002.

[3] Roels S, Moonen P, de Proft K, Carmeliet J. A coupled discrete-continuum approach to simulate moisture effects on damage processes in porous materials. Comput Method Appl Mech Eng 2006;195:7139-53.

[4] Moonen P. Continuous-discontinuous modelling of hygrothermal damage processes in porous media. Ph.D. thesis; Katholieke Universiteit Leuven; 2009.

[5] Ožbolt J, Balabanić G, Periškić G, Kušter M. Modelling the effect of damage on transport processes in concrete. Constr Build Mater 2010;24:1638-48.

[6] Réthoré J, de Borst R, Abellan MA. A two-scale approach for fluid flow in fractured porous media. Int J Numer Meth Eng 2007:71:780-800.

[7] Alfaiate J, Moonen P, Sluys L, Carmeliet J. On the use of strong discontinuity formulations for the modeling of preferential moisture uptake in fractured porous media. Comput Method Appl Mech Eng 2010;199:2828-39.

[8] Pease B. Influence of concrete cracking on ingress and reinforcement corrosion. Ph.D. thesis; Department of Civil Engineering, Technical University of Denmark; 2010.

[9] Hillerborg A, Modeer M, Petersson P. Analysis of crack formation and crack growth in concrete by means of fracture mechanics and finite elements. Cement Concrete Res 1976;6:773-82.

[10] Shah S, Choi S. Nondestructive techniques for studying fracture processes in concrete. Int J Fracture 1999;98:351-9.

[11] Ohtsu M, Watanabe H. Quantitative damage estimation of concrete by acoustic emission. Constr Build Mater 2001;15:217-24.

[12] Sutton M, Wolters W, Peters W, Ranson W, McNeill S. Determination of displacements using an improved digital correlation method. Image Vision Comput 1983;1:133-9.
[13] Hild F, Roux S. Digital image correlation: from displacement measurement to identification of elastic properties - a review. Strain 2006;42:69-80.

[14] Choi S, Shah S. Measurement of deformations on concrete subjected to compression using image correlation. Exp Mech 1997;37:307-13.

[15] Corr D, Accardi M, Graham-Brady L, Shah S. Digital image correlation analysis of interfacial debonding properties and fracture behavior in concrete. Eng Fract Mech 2007;74(1)

[16] Sutton M, Orteu JJ, Schreier H. Image correlation for shape, motion and deformation measurements: basic concepts, theory and applications. Springer; 2009.

[17] Drchalová J, Černý R. A simple gravimetric method for determining the moisture diffusivity of building materials. Constr Build Mater 2003;17: 223-8.

[18] Carmeliet J, Hens H, Roels S, Adan O, Brocken H, Černý R, et al. Determination of the liquid water diffusivity from transient moisture transfer experiments. J Therm Envel Build Sci 2004;27:277-304.

[19] Roels S, Carmeliet J. Analysis of moisture flow in porous materials using microfocus x-ray radiography. Int J Heat Mass Tran 2006;49:4762-72.

[20] Baroghel-Bouny V, Mainguy M, Lassabatere T, Coussy O. Characterization and identification of equilibrium and transfer moisture properties for ordinary and high-performance cementitious materials. Cement Concrete Res 1999;29: 1225-38.

[21] Gummerson R, Hall C, Hoff W. Water movement in porous building materialsii. hydraulic suction and sorptivity of brick and other masonry materials. Build Environ 1980;15:101-8.

[22] Vejmelková E, Pavliková M, Jerman M, Černý R. Free water intake as means of material characterization. J Build Phys 2009;33:29-44.

[23] Janssen H, Blocken B, Carmeliet J. Conservative modelling of the moisture and heat transfer in building components under atmospheric excitation. Int J Heat Mass Tran 2007:50:1128-40.

[24] Roels S, Vandersteen K, Carmeliet J. Measuring and simulating moisture uptake in a fractured porous medium. Adv Water Resour 2003;26:237-46.

[25] de Freitas VP, Abrantes V, Crausse P. Moisture migration in building walls analysis of the interface phenomena. Build Environ 1996;31:99-108.

[26] Vandersteen K, Carmeliet J, Feyen J. A network modeling approach to derive unsaturated hydraulic properties of a rough-walled structure. Transport Porous Med 2003;50:197-221.

[27] van Genuchten M. A closed-form equation for predicting the hydraulic conductivity of unsaturated soils. Soil Sci Soc Am J 1980;44:892-8.

[28] Durner W. Hydraulic conductivity estimation for soils with heterogeneous pore structure. Water Resour Res 1994;30:211-23.

[29] Hall C, Kalimeris A. Water movement in porous building materials-v. absorption and shedding of rain by building surfaces. Build Environ 1982;17:257-62.

[30] Blocken B, Carmeliet J. A review of wind-driven rain research in building science. J Wind Eng Ind Aerod 2004;92:1079-130. 